\title{
O passado em bytes: notas sobre os usos da internet nos livros didáticos de História
}

The past in bytes: notes on the uses of the Internet in history textbooks

Dilton C. S. Maynard*

Marcos Silva**

Neste texto apresentamos algumas considerações pontuais sobre a presença da internet nos livros didáticos. Afinal de contas, a popularização da internet nas primeiras décadas do século XXI praticamente obrigou as editoras e os autores a considerarem o potencial da rede mundial de computadores no processo de ensino-aprendizagem. Por conta disso, a inserção de endereços eletrônicos em livros didáticos e em seus respectivos Manuais do Professor tornou-se frequente.

Todavia, como tem sido feito uso da web? Ao que tudo indica, timidamente. Em sua maioria, os livros didáticos apenas indicam o site, mas sem oferecer aos professores e aos alunos orientações que permitam uma correta abordagem dos conteúdos constantes em tais páginas. Se levarmos em conta que o livro didático permanece ainda como o grande aliado - em alguns casos, o único - disponível ao professor, questionar o que ele indica, assim como saber utilizá-lo adequadamente, é fundamental. Por isso, chama a nossa atenção o pouco zelo conferido ao modo como as páginas eletrônicas tem sido exploradas enquanto suportes didáticos para o ensino da História.

Desse modo, considerando a especificidade de nossa seção aqui na História Hoje, oferecemos uma reflexão sobre a internet, possivelmente o mais poderoso suporte pedagógico do novo século, e as suas ressonâncias na abordagem da aventura humana no tempo. ${ }^{1}$

De modo a exemplificar esse uso desatento, vamos até a home page de uma prestigiosa universidade paulista. ${ }^{2}$ Ali havia um curioso espaço. Tratava-se de

\footnotetext{
* Departamento de História, Universidade Federal de Sergipe.

** Departamento de História, Universidade Federal de Sergipe.
} 
um 'museu virtual', um site dedicado a educar crianças na leitura de obras de arte. Entre os quadros exibidos (e traduzidos) para a criançada está Retirantes, um óleo sobre tela pintado em 1944 por Cândido Portinari. A descrição a seguir, retirada do site, embora longa, merece ser citada pelas imagens que (re) produzia:

A obra Retirantes representa o povo nordestino ... Retirantes mostra a necessidade que o povo tem em abandonar sua terra em busca de uma vida melhor em outra parte do país (por isso o nome Retirantes - retirante é o homem nordestino que viaja de onde mora a outro lugar em busca de água e comida, fugindo da seca) ... Candinho precisava mostrar o sofrimento do povo brasileiro, pois ele sofria muito com o sofrimento de sua gente ... Os personagens ilustrados por ele são reais, muito magros (raquíticos), famintos. Eles estão descalços, com aparência horrível, dando a impressão de estarem sujos. Uma das crianças - de um total de cinco - tem um corpo muito feio e deformado. Outra tem barriga-d'água. Os dois homens - o chefe da família e seu pai - têm a aparência de quem viveu uma vida muito dura no sertão nordestino. A mulher - a esposa - carrega uma sacola. Isso quer dizer que ela está em busca de uma vida melhor. Observe, amiguinho, o olhar destas pobres e tristes pessoas: olhar que não traz esperança por uma vida melhor. As partes de corpo à mostra não têm pele, apenas ossos e músculos fracos. As roupas estão rasgadas e não cobrem todo o corpo. O céu é mostrado em cinza escuro, apesar de não ter nuvens. É como que um céu seco, sem água (o Nordeste é seco), mas também sem luz ... Repare, amigo, como há muitos urubus à procura de alimento, seja um gado morto pela seca ou os próprios retirantes. Não há plantas nem flores. Assim, Candinho mostra o sertão em sua forma mais triste. O chão traz só restos de ossos de gado e pedrinhas. Retirantes é uma das obras mais tristes de Candinho, mas é real, pois mostra a realidade do povo nordestino.

Todos os grifos são nossos. Este texto, encontrado na internet em 2004, sugere que as representações elaboradas tempos atrás ainda estão em funcionamento. Os sinais da miséria povoam a análise do quadro que, segundo se anuncia, 'representa o povo nordestino'. O texto, destinado ao público infantil (daí o recurso ao apelido 'Candinho'), supunha informar sobre o que é o Nordeste. É no tempo presente que ela se inscreve: espaço de gente faminta, céu seco e sem luz; lugar sombrio do qual se foge com os poucos trapos que se tem. Terra sem esperança, na qual 'o chão traz só restos de ossos de gado e pedrinhas'. Por mais de uma vez, a 'realidade' das imagens pintadas por 
Portinari era afirmada na página eletrônica. Uma realidade construída em sintonia com outros campos, como a literatura regionalista dos anos 1930 .

Conforme Durval Muniz de Albuquerque, a produção imagética sobre o Nordeste teve em Portinari um grande colaborador. Um contribuinte fundamental para que o chamado 'romance de 30' e seus personagens ganhassem materialidade: "o retirante esquelético de Portinari, com seus bordões para se apoiar, com seus meninos barrigudos e tristes, com suas trouxas na cabeça, se tornou imagem difícil de ser esquecida e de se fugir quando se pretende mostrar a realidade nacional". ${ }^{3}$

Envernizado pelo suporte cibernético, o texto, ao propor-se inovador, repete e reforça estereótipos. Paralisa o tempo, cristaliza uma imagem grotesca e homogeneizadora e a difunde via ciberespaço. Através da menção a sites, blogs e outros suportes eletrônicos, a pretensão parece ser conferir aos livros didáticos um caráter atualizado. Todavia, é sempre conveniente lembrar que a internet oferece vantagens, mas também perigos, problemas a serem atentamente observados.

Variáveis como acessibilidade, reprodutibilidade, manipulabilidade e hipertextualidade convivem com a inacessibilidade, a baixa interatividade, o plágio virtual e as dificuldades em torno da autoria. Contudo, não acreditamos que tais dificuldades sejam suficientes para que deixemos de lado os recursos digitais. O que se deve fazer é reforçar a atenção em aspectos centrais que podem ajudar a manter a qualidade do material utilizado quando a preocupação é de ordem didática.

O critério de acessibilidade é fundamental. Ao planejar o uso de uma página eletrônica, é preciso observar com cautela as suas condições. Páginas que oferecem restrições à navegação, exigindo cadastros complexos ou mesmo pagamento dos usuários, podem servir de exemplo entre os espaços que dificultam o acesso. Há outros problemas a serem considerados, tais como: a confusão de conteúdos, que ocorre quando a obra indica determinado assunto, mas o endereço por ela oferecido não corresponde ao tema indicado; a existência de endereços que não funcionam mais; a indicação de endereços incorretamente impressos nos livros; a demasiada oferta de páginas em idiomas estrangeiros; a demora da página para que todo o seu conteúdo possa ser visualizado; o uso de imagens em baixa resolução, que não podem ser ampliadas, 
bem como a predominância de fontes em tamanho único. São muitos os obstáculos.

Tais problemas comprometem o acesso ao conteúdo proposto por cada livro. Por isso, ao indicar uma página para o aluno é preciso considerar as possibilidades de acessibilidade, assim como os percalços comuns a ela: sites inativos, páginas que cobram pelo acesso, exigem usuários previamente cadastrados, possuem endereços divergentes dos conteúdos ou se mostram demasiadamente lentas na apresentação dos conteúdos iniciais. Qual a relevância disto? Ora, dificuldades como essas podem afastar alunos e professores de um uso pedagógico da internet, numa lamentável confusão provocada pelo uso descuidado da rede mundial de computadores. ${ }^{4}$

E qual a importância de considerarmos se um site exige ou não cadastro prévio para ser acessado? Basta considerarmos que diante de um obstáculo como este, o visitante se desloque para um ambiente que lhe pareça menos burocrático, menos exigente à visitação. $\mathrm{O}$ resultado desse desvio pode ser vislumbrado quando - como mostraram pesquisadores norte-americanos - $\mathrm{o}$ site mais acessado sobre Thomas Jefferson não é necessariamente um site de referência, mas o blog de um colecionador, de um diletante, alguém bem distante da Academia. ${ }^{5}$

Se o livro didático resolver investir em recomendar e explorar sites, o suporte metodológico para lidar com as páginas da internet deve ser oferecido pelo Manual do Professor, já que este é concebido para ser uma ferramenta de suporte impresso diferenciada, em seu conteúdo e objetivos, do livro didático do aluno. Para cumprir esse papel no planejamento das melhores estratégias de ensino-aprendizagem, o Manual do Professor deve se apresentar como uma obra detalhada em suas sugestões e sintonizada com as dificuldades de implementação de determinadas experiências em sala de aula. O Manual deve nortear o professor sobre os caminhos que ele pode tomar ao explorar determinado endereço eletrônico, orientando o docente sobre as vantagens e percalços que a página indicada oferece. As páginas devem oferecer possibilidades de exploração de fontes históricas, devem atuar como complementos do material impresso.

Portanto, é desaconselhável que o Manual do Professor se limite a listar inúmeras páginas da internet sem oferecer a possibilidade de um efetivo suporte metodológico que ajude a responder à pergunta: “o que podemos fazer 
com a internet nas aulas de História?". Tal questionamento nos leva a outro critério considerado na avaliação das páginas eletrônicas indicadas, a funcionalidade.

Insistimos, é preciso atenção quando a internet for indicada ao aluno ou ao professor, e sempre que ela for utilizada para a elaboração de textos e atividades. Afinal de contas, como qualquer outro tipo de suporte, a rede mundial de computadores é falível, seletiva e muitas vezes inadequada a certas abordagens. Por isso, o cuidado deve ser constante.

Não se trata de limitar a discussão aos sites bons ou ruins. O que exige a nossa reflexão é o fato incontestável de que os vários tipos de páginas eletrônicas têm sido explorados como se formassem um grupo homogêneo e facilmente manejável. Longe disso, os diferentes websites possuem uma tipologia própria, carregam consigo propostas ideológicas e merecem ser pensados dentro das suas especificidades.

Como se pode ver, vivemos uma situação desconfortável. Em primeiro lugar, pela desconfiança que muitos profissionais da educação ainda demonstram em relação à web. Evidentemente, as sucessões de escândalos, fraudes e crimes virtuais diariamente noticiados justificam, ao menos em parte, essa atitude. Todavia, é salutar considerar que fazer de conta que a internet não existe não resolve o problema.

Porém, a mera inserção de enormes listagens e de atividades a partir da rede mundial de computadores também não traz solução. De nada adianta encontrar obras que possuem dezenas de indicações de páginas eletrônicas se não há uma reflexão metodológica adequada sobre o que se pode e se deve fazer com esse material. Sendo assim, como proceder? O professor deve, sempre que encontrar indicações de sites ou sugestões de atividades através deles, ter o cuidado de conhecer primeiro o ambiente proposto. Alguns cuidados básicos podem ajudar a evitar maiores problemas no uso das páginas.

Uma pergunta fundamental a ser feita é: os conteúdos dialogam satisfatoriamente com aquilo que se pretende abordar em classe? Muitas vezes, ficamos empolgados com bons sites que oferecem uma imensidão de informações. Porém, não é disso que o aluno precisa, mas de páginas que contribuam adequadamente para o seu desenvolvimento. De nada adiantará deixar o estudante sem saber por onde poderá começar sua navegação. Por isso, é importante ao professor ser ele mesmo um usuário antecipado das páginas, verificando as 
possibilidades pedagógicas de uso, observando as fontes utilizadas pelo site. Não são poucas aquelas que simplesmente reproduzem os conteúdos dos livros didáticos, apenas alterando a ordem ou a qualidade de imagens e mapas.

Também vale a pena olhar com cuidado as muitas vezes imensas listagens de páginas da internet constantes nos livros didáticos (tanto no exemplar do aluno, quanto no Manual do Professor). Acredite: o simples exercício de observar poderá ajudar a perceber aquelas mais recorrentes e o nível de cuidado da obra com as suas indicações.

E tenha certeza, caro colega professor: nem tudo é ruim. O zelo com que certas páginas eletrônicas são exploradas em algumas obras pode torná-las auxiliares valiosos no cotidiano da sala de aula. Páginas de qualidade podem enriquecer as aulas, pois nelas podemos ampliar mapas, detalhar imagens, encontrar reproduções de fontes históricas, vídeos com registros de acontecimentos mencionados nos textos dos livros. Enfim, como escreveu o historiador norte-americano Robert Darnton, a internet "pode fazer a História cantar". ${ }^{6}$

Portanto, cabe lembrar ao professor que o uso dos chamados 'ambientes telemáticos' deve ser feito da forma mais contextualizada possível. Longe de ser apenas uma versão eletrônica da página de um livro, uma mera reprodução de um texto impresso e desatualizado, uma página da internet deve se mostrar integrada aos conteúdos abordados pelo livro do aluno e, ao mesmo tempo, deverá ser amparada pelo Manual do Professor quanto ao seu potencial de uso, além de possibilitar o máximo de opções de interatividade. Desse modo, é importante avaliar como as páginas são incorporadas a cada livro didático, se seu uso ambiciona realmente uma ampliação na abordagem, se este ou aquele site é um aliado ou, por suas características ou pela forma com que é apresentado, um obstáculo à construção do conhecimento histórico. ${ }^{7}$

\section{NOTAS}

${ }^{1}$ ROSENZWEIG, Roy. Scarcity or Abundance? Preserving the past. In: Clio Wired: the future on the past in the digital age. New York: Columbia University Press, 2011, p.3-27.

${ }^{2}$ www.puccampinas.edu.br/404.aspx? urlFrom=centros/clc/jornalismo/projetosweb/1998/ portinari/retirante.html/; Último acesso em: 2 maio 2005.

${ }^{3}$ ALBUQUERQUE JÚNIOR, Durval Muniz de. A Invenção do Nordeste e outras artes. Prefácio de Margareth Rago. Recife: FJN; Massangana; São Paulo: Cortez, 1999, p.249-250. 
${ }^{4}$ Cf. CHARTIER, Roger. A história na era digital. In: A história ou a leitura do tempo. Belo Horizonte: Autêntica, 2009, p.60-61.

${ }^{5}$ Sobre isto ver: COHEN, Daniel J.; ROSENZWEIG, Roy. Digital History: a guide to gathering, preserving, and presenting the past on the web. Philadelphia: University of Pennsylvania Press, 2006.

${ }^{6}$ DARNTON, Robert. As notícias em Paris: uma pioneira sociedade da informação. In: . Os dentes falsos de George Washington: um guia não convencional para o século XVIII. Trad. José Geraldo Couto. São Paulo: Companhia das Letras, 2005. p.40-89.

${ }^{7}$ Ver também: BROCKMAN, John (Org.). Is the Internet changing the way you think? New York: Harper Perennial, 2011. 